\title{
HIDROGEOQUÍMICA COMO INDICADOR DE INTERCONEXÃO ENTRE AQÜÍFEROS NA CHAPADA DO ARARIPE UTILIZANDO O APLICATIVO PHREEQC
}

\author{
Carlos José Freire MACHADO ${ }^{1}$ \\ Maria Marlúcia Freitas SANTIAGO ${ }^{1}$ \\ Luiz Alberto Ribeiro MENDONÇA ${ }^{1}$ \\ Horst FRISHKORN ${ }^{2}$ \\ Josué MENDES FILHO ${ }^{1}$
}

\begin{abstract}
RESUMO
Foi traçada a evolução hidroquímica através de uma inversão hidrogeoquímica, utilizando o aplicativo PHREEQC, para calcular a transferência molar de minerais entre a água mineralizada e o meio por onde ela flui, ocorrida entre os Sistemas Aqüíferos Superior e Médio da Chapada do Araripe, localizada na região nordeste do Brasil, ao sul do Estado do Ceará, noroeste de Pernambuco e Sudeste do Piauí. A inversão hidroquímica foi realizada a partir de duas amostras d'água: uma com características do Sistema Aqüífero Superior, a água inicial, e outra com características do Sistema Aqüífero Médio, a água final, suposta evoluída hidrogeoquimicamente da água inicial. $\mathrm{Na}$ inversão hidroquímica foram considerados processos de precipitação e/ou dissolução de minerais contidos nas rochas das formações geológicas por onde a água flui, trocas iônicas com argilominerais, além de reações redox características da presença de matéria orgânica e microorganismos em subsuperfície. Os resultados estão de acordo com a existência de conexões hídricas entre os diferentes sistemas aqüíferos concordando com o modelo fenomenológico para a circulação de água subterrânea proposto para a região.
\end{abstract}

\begin{abstract}
We traced the hydro-chemical evolution, through hydrogeochemical inversion, utilizing the software PHREEQC to calculate the molar transfer between the mineralized water and the medium where it flows. This method was applied to waters from the Upper and Medium Aquifer Systems of Araripe Plateau, localized in northeastern Brazil, devided between the south of Ceará, the northwest of Pernambuco and southeast of Piauí. The hydro-chemical inversion was based on two water samples: one with the characteristics of the Upper Aquifer System, the initial water, and the other one with the characteristics of the Medium Aquifer System, the final water, supposed to have evolved hydrogeochemically from the initial water. In the hydro-chemical inversion, processes of precipitation and/or dissolution of rock minerals that compose the geologic formations where the water flows, ionic changes with clay minerals, and also redox reactions because ofthe presence of organic matter and microorganisms in subsurface. The results evidence the existence of hydraulic connections between the distinct aquifer systems and agrees with the phenomenological model for groundwater flow proposed for these aquifer systems.
\end{abstract}

Palavras - chave: PHREEQC, modelagem geoquímica, Chapada do Araripe.

\footnotetext{
${ }^{1}$ Depto. Física - UFC; machado@fisica.ufc.br

${ }^{2}$ Depto. Engenharia Hidráulica e Ambiental - UFC; cariri@ufc.br
} 


\section{Introdução}

Para identificar e quantificar os processos hidrogeoquímicos ocorridos nos sistemas aqüíferos da Chapada do Araripe, parte da Bacia Sedimentar do Araripe (Figura 1), foi desenvolvido um modelo hidrogeoquímico de circulação que detalha o modelo fenomenológico proposto por
SANTIAGO et al. (1997). Neste modelo, a água subterrânea infiltra-se através das formações Exu e Arajara, que constituem o Sistema Aqüífero Superior, continua seu caminho de fluxo atravessando as falhas geológicas do aquiclude Santana até atingir a Formação Rio da Batateira, no Sistema Aqüífero Médio.

Figura 1 - A linha destacada no centro do mapa indica os limites geográficos da Bacia. As coordenadas estão em UTM, com meridiano central igual a $39^{\circ}$. As formações hachuradas representam aqüíferos.

Mapa da Bacia Sedimentar do Araripe com esboço esquemático de sua estratigrafia.

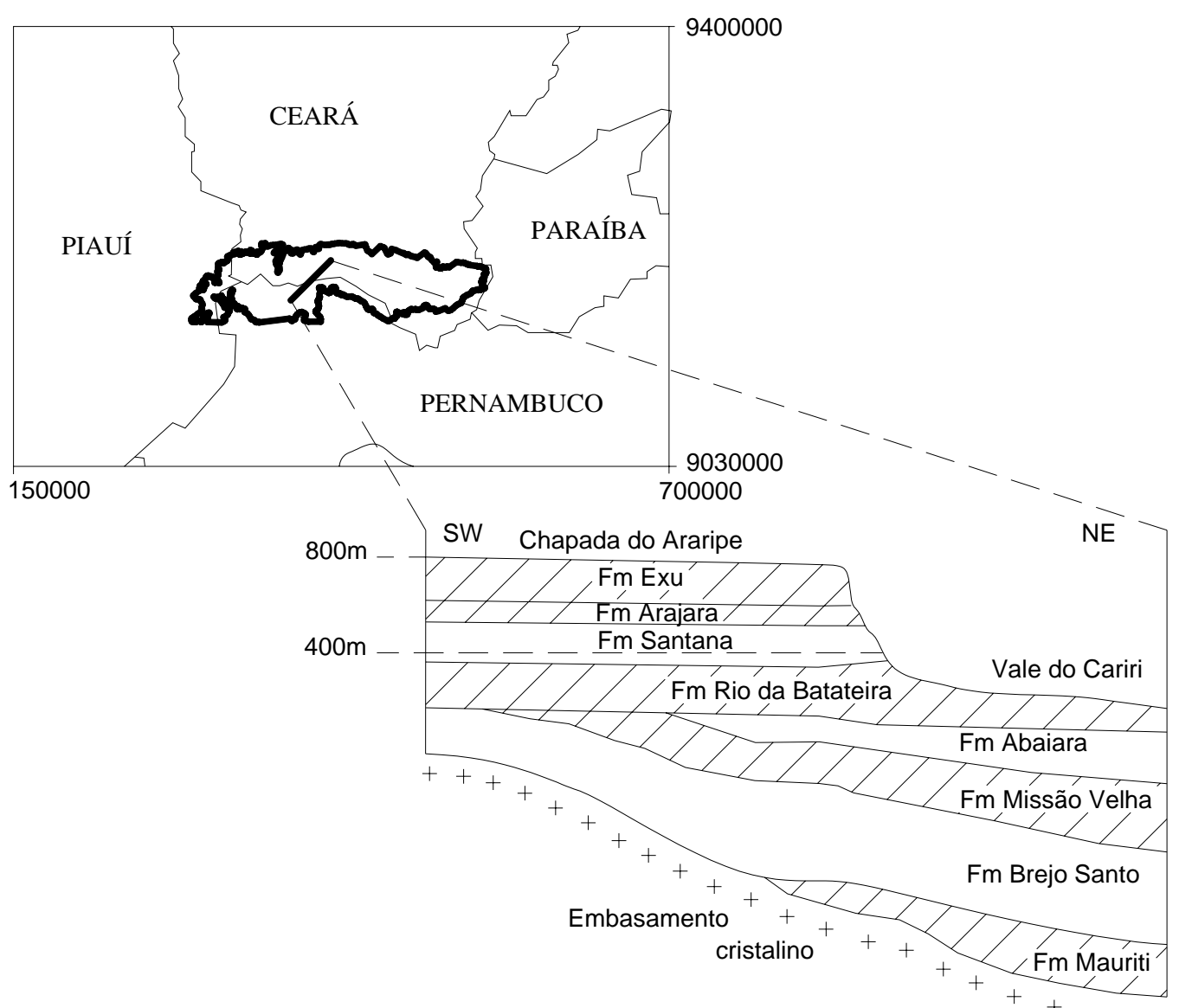

Para identificar e quantificar os processos termodinâmicos responsáveis pela evolução hidrogeoquímica da água subterrânea foram usados processos que podem alterar de alguma forma a composição química da água, tais como a dissolução/precipitação de minerais, troca iônica, etc. Os processos utilizados nesta simulação incluem a precipitação/dissolução de calcários (calcita e dolomita), gipsita, minerais de ferro (goethita e pirita), feldspatos e argilas; de processos de oxiredução induzidos pela matéria orgânica presente nos aqüíferos e de processos de troca iônica entre os íons metálicos adsorvidos nas argilas.

\section{A Área}

A Bacia Sedimentar do Araripe é localizada na região compreendida pelo sul do Estado do Ceará, noroeste do Estado de Pernambuco e sudeste do Piauí, sendo o Ceará o detentor da maior área da Bacia, na sua parte setentrional. É formada por um planalto, a Chapada do Araripe, e por uma planície, o vale do Cariri, e detém a mais 
importante reserva de água subterrânea do Estado do Ceará.

A coluna estratigráfica da Bacia do Araripe repousa sobre um embasamento de rochas precambrianas e é constituída, do topo para a base, pelos grupos Araripe, Vale do Cariri e formação Mauriti. O grupo Araripe é constituído pelas formações Exu, no topo, Arajara, Santana e Rio da Batateira, na sua base (PONTE e APPI, 1990). A este grupo se restringe este trabalho, traçando a evolução hidrogeoquímica da água subterrânea desde sua entrada no chamado Sistema Aqüífero Superior, composto pelas formações Exu e Arajara, atravessando o aquiclude Santana, através de falhas e fraturas geológicas e chegando ao aqüífero Rio da Batateira, na base deste grupo (Figura 1), de acordo com modelo proposto por SANTIAGO et al. (1997).

A recarga da água subterrânea na chapada ocorre no aqüífero Exu (no topo da Chapada), constituído, litologicamente, de uma seqüência monótona de arenitos friáveis, argilosos, de granulometria variável, geralmente caulínicos, onde se intercalam leitos de arenitos grosseiros, conglomeráticos, friáveis, constituindo litofácies típicas de depósitos fluviais (PONTE e APPI, 1990). Os solos derivados destes arenitos são constituídos por 99\% de quartzo hialino com grãos de aderência ferruginosa e $1 \%$ de concreções ferroargilosas e ferruginosas (JACOMINE et al., 1973).

O aqüífero Arajara, subjacente ao aqüífero Exu, é constituído por uma seqüência de siltitos, argilitos e arenitos finos argilosos, com litofácies típicas de ambientes lacustres rasos (PONTE; APPI, 1990). Devido à falta de dados mineralógicos específicos, assumiu-se para esta formação uma mineralogia semelhante a da formação Exu, haja vista ambas terem litologias semelhantes. Esta suposição é reforçada pela baixa condutividade elétrica $(\approx 85 \mathrm{~S} / \mathrm{cm})$ das águas explotadas por poços tubulares e cacimbas neste aqüífero (MENDONÇA, 2001).

$\mathrm{Na}$ seqüência espaço-temporal, parte da água subterrânea proveniente do aqüífero Arajará passa pelo aquiclude Santana, através das fraturas geológicas que atravessam suas rochas. Este aquiclude é constituído, do topo para a base, pelos membros Romualdo, Ipubí e Crato (BEURLEN, 1971). Nele ocorrem os mais importantes eventos hidrogeoquímicos do fluxo regional.

O membro Romualdo é constituído por intercalações de folhelhos, margas, calcários e lentes de arenitos friáveis, com espessura que chega a $60 \mathrm{~m}$ (OLIVEIRA, 1998). O membro Ipubi é caracterizado por uma camada evaporítica com espessura média de $30 \mathrm{~m}$, formada principalmente por gipsita $\left(\mathrm{CaSO}_{4} .2 \mathrm{H}_{2} \mathrm{O}\right)$ e anidrida $\left(\mathrm{CaSO}_{4}\right)$ (SILVA, 1983 e 1988). O membro Crato é composto, do topo para a base, de calcários micríticos argilosos e folhelhos calcíferos, laminados, representando fácies centrais de um sistema deposicional lacustre, com espessura média da ordem de 50 m (SILVA, 1983). Este membro possui uma grande quantidade de Carbono Orgânico Total (COT), da ordem de $25 \%$ (ASSINE, 1992), o que propicia atividades metabólicas de microorganismos heterotróficos, que levam à oxidação da matéria orgânica.

A água proveniente das fraturas chega ao aqüífero Rio da Batateira, subjacente ao aquiclude Santana. Este aqüífero é constituído litologicamente por arenitos argilosos médios a finos, siltitos argilosos e folhelhos betuminosos, fossilíferos, com uma espessura aproximada de 200 m (PONTE e APPI, 1990). A mineralogia, obtida dos solos onde aflora esta formação, indica a presença de $100 \%$ de quartzo vítreo incolor, contendo grãos com aderência ferruginosa, concreção manganosa, concreção argiloferruginosa e feldspato potássico bastante intemperizado (JACOMINE et al., 1973).

\section{Processos químicos compatíveis com os minerais da Chapada do Araripe}

De acordo com a litologia e mineralogia das formações geológicas por onde a água infiltra, os processos de interação água-rocha na Bacia Sedimentar do Araripe podem ser descritos pela seguinte seqüência espaço-temporal:

No aqüífero Exu a presença de $\mathrm{CO}_{2}$ no solo e/ou subsolo proporciona a ocorrência de três importantes reações: dissolução do gás carbônico na água (Eq.1); interação do gás dissolvido com a água produzindo ácido carbônico (Eq. 2); primeira e segunda dissociação do ácido carbônico em água (Eq. 3 e 4, respectivamente), originando carbonatos e bicarbonatos.
1. $\mathrm{CO}_{2(g)} \rightleftharpoons \mathrm{CO}_{2(\mathrm{aq})}, \mathrm{K}=10^{-1,5}$
2. $\mathrm{CO}_{2(a q)}+\mathrm{H}_{2} \mathrm{O} \rightleftharpoons \mathrm{H}_{2} \mathrm{CO}_{3}, \mathrm{~K}=10^{-2,8}$ 
3. $\mathrm{H}_{2} \mathrm{CO}_{3}{ }^{*} \rightleftharpoons \mathrm{H}^{+}+\mathrm{HCO}_{3}{ }^{-}, K_{\mathrm{a}, 1}=10^{-6,3}$ 4. $\mathrm{HCO}_{3}{ }^{-} \rightleftharpoons \mathrm{H}^{+}+\mathrm{CO}_{3}{ }^{2-}, \mathrm{K}_{\mathrm{a}, 2}=10^{-10,3}$.

$\mathrm{Na}$ Eq. $3 \mathrm{H}_{2} \mathrm{CO}_{3}{ }^{*}$ é uma espécie hipotética representando conjuntamente $\mathrm{H}_{2} \mathrm{CO}_{3}$ e $\mathrm{CO}_{2}^{-2}$, devido à dificuldade de distinguir analiticamente as duas espécies químicas.

No aquiclude Santana, as presenças de calcário e dolomita nos membros Romualdo e Crato e de gipsita no membro Ipubi propiciam a precipitação de calcita (Eq. 5) (por efeito do íon comum, o $\mathrm{Ca}^{2+}$ ) e a dissolução de dolomita (Eq. 6) e gipsita (Eq. 7).
5. $\mathrm{CaCO}_{3 \text { (calcita) }} \rightleftharpoons \mathrm{Ca}^{2+}+\mathrm{CO}_{3}{ }^{2-}$, $K_{\text {so(calcita) }}=10^{-8,48}$

6. $\mathrm{CaMg}\left(\mathrm{CO}_{3}\right)_{2 \text { (dolomita) }} \rightleftharpoons \mathrm{Ca}^{2+}+\mathrm{Mg}^{2+}+$ $2 \mathrm{CO}_{3}{ }^{2-}, \quad K_{\text {so(calcita) }}=10^{-17,09}$

7. $\begin{aligned} & \mathrm{CaSO}_{4 \text { (gipsita) }} \rightleftharpoons \mathrm{Ca}^{2+}+\mathrm{SO}_{4}{ }^{2-} \text {, } \\ & K_{\text {so(gipsita) }}=10^{-4,58}\end{aligned}$

A presença da relativamente alta concentração de ferro na água do aqüífero Rio da Batateira e da alta concentração de sulfatos provenientes do membro Ipubi da formação Santana, juntamente com a grande quantidade de matéria orgânica no membro Crato, propiciarão processos termodinâmicos de oxiredução anaeróbicos através de atividades microbiológicas (Eq. 8), onde $\mathrm{CH}_{2} \mathrm{O}$ representa genericamente, matéria orgânica. Deste modo, com a dissolução de goethita (Eq. 9), $\mathrm{Fe}(\mathrm{III+})$ entrará na solução reduzindo-se a $\mathrm{Fe}(\mathrm{II+})$ de acordo com a Eq. 10 e com a dissolução de gipsita (Eq. 7), o $\mathrm{S}(\mathrm{VI}+)$ nos sulfatos reduzir-se-á para S(II-) nos sulfetos (Eqs.11e 12).

8. $\mathrm{CH}_{2} \mathrm{O}+\mathrm{H}_{2} \mathrm{O} \rightleftharpoons \mathrm{CO}_{2}+4 \mathrm{H}^{+}+4 \mathrm{e}^{-}$,

9. $\mathrm{FeOOH}_{(s)(\text { goethita) }}+3 \mathrm{H}^{+} \rightleftharpoons \mathrm{Fe}^{3+}+$ $2 \mathrm{H}_{2} \mathrm{O}, \quad K=10^{-1,0}$

10. $\mathrm{CH}_{2} \mathrm{O}+4 \mathrm{Fe}^{3+}+\mathrm{H}_{2} \mathrm{O} \rightleftharpoons \mathrm{CO}_{2}+$ $4 \mathrm{Fe}^{2+}+4 \mathrm{H}^{+}$

11. $\mathrm{SO}_{4}=+9 \mathrm{H}^{+}+8 \mathrm{e}^{-} \underset{K=10^{33,65}}{\rightleftharpoons} \mathrm{HS}^{-}+4 \mathrm{H}_{2} \mathrm{O}$, $K=10^{33,65}$

12. $4 \mathrm{CH}_{2} \mathrm{O}+2 \mathrm{SO}_{4}{ }^{=}+3 \mathrm{H}^{+} \rightleftharpoons \mathrm{H}_{2} \mathrm{~S}+$ $\mathrm{HS}^{-}+4 \mathrm{CO}_{2}+4 \mathrm{H}_{2} \mathrm{O}$,
A existência de sulfetos e íons ferrosos em solução implica na formação de pirita $\left(\mathrm{FeS}_{2}\right)$ (Eq.13), que é um mineral de solubilidade muito baixa e tenderá, portanto, a precipitar-se.

13. $\begin{aligned} \mathrm{FeS}_{2(\mathrm{~s})}+2 \mathrm{H}^{+}+2 \mathrm{e}^{-} \underset{\mathrm{C}^{-18,479}}{\rightleftharpoons} \mathrm{Fe}^{2+}+2 \mathrm{HS}^{-}, & \end{aligned}$

Como o quartzo e as argilas são produtos finais nos processos de intemperismo, é provável que ocorram precipitações de argilas, que serão representadas na simulação hidroquímica pelas montmorilonitas cálcica (Eq. 14) e sódica (Eq. 15),

14. $\mathrm{Ca}_{0,165} \mathrm{Al}_{2,33} \mathrm{Si}_{3,67} \mathrm{O}_{10}(\mathrm{OH})_{2}+12 \mathrm{H}_{2} \mathrm{O} \rightleftharpoons$ $0,165 \mathrm{Ca}^{2+}+2,33 \mathrm{Al}(\mathrm{OH})_{4}^{-}+3,67 \mathrm{H}_{4} \mathrm{SiO}_{4}$ $+2 \mathrm{H}^{+}, \quad K=10^{-45,027}$

15. $\mathrm{Na}_{0,5} \mathrm{Al}_{1,5} \mathrm{Mg}_{0,5} \mathrm{Si}_{4} \mathrm{O}_{10}(\mathrm{OH})_{2}+10 \mathrm{H}_{2} \mathrm{O} \rightleftharpoons$ $0,5 \mathrm{Na}^{+}+0,5 \mathrm{Mg}^{2+}+1,5 \mathrm{Al}(\mathrm{OH})_{4}^{-}+$ $4 \mathrm{H}_{4} \mathrm{SiO}_{4}$

Outro processo considerado na simulação hidrogeoquímica, além daqueles de dissolução, precipitação e oxiredução descritos, é o processo de troca iônica entre íons metálicos adsorvidos em argilas devido principalmente à presença de arenitos argilosos nas formações Abaiara e Rio da Batateira. Desta forma, admitiu-se trocas entre os íons $\mathrm{Ca}^{2+}, \mathrm{Mg}^{2+}$ e $\mathrm{Na}^{+}$, tendo como substrato argila, representada pelo "elemento químico" X nas Eqs. 16, 17 e 18.

16. $\mathrm{Ca}^{2+}+2 \mathrm{X}^{-} \rightleftharpoons \mathrm{CaX} 2 ; K=10^{0,8}$

17. $\mathrm{Mg}^{2+}+2 \mathrm{X}^{-} \rightleftharpoons \mathrm{CaX} 2 ; K=10^{0,6}$

18. $\mathrm{Na}^{+}+\mathrm{X}^{-} \rightleftharpoons \mathrm{NaX} ; \quad K=10^{\circ}=1$

\section{Resultados e Discussões}

Para o cálculo das transferências molares entre as formações geológicas e a água subterrânea através da inversão geoquímica, usando o aplicativo PHREEQC, elegeu-se uma amostra d'água do aqüífero Exu como "inicial" e outra do aqüífero Rio da Batateira como "final" (Tabela 1). Estas duas amostras representam, respectivamente, 0 início e o fim do processo de evolução hidrogeoquímica decorrente das características litológicas e mineralógicas das formações geológicas existentes ao longo do caminho de fluxo, conforme descrito anteriormente na seção 2 . 
Tabela 1 - Hidroquímica das amostras de águas subterrâneas utilizadas na modelagem.

\begin{tabular}{|c|c|c|c|c|c|c|c|c|c|c|c|}
\hline \multirow[t]{2}{*}{ Amostra } & \multirow[t]{2}{*}{$\mathrm{PH}$} & \multirow[t]{2}{*}{$\mathrm{T}\left({ }^{\circ} \mathrm{C}\right)$} & \multirow{2}{*}{$\begin{array}{c}\text { CE } \\
(\mu \mathrm{S} / \mathrm{cm})\end{array}$} & \multicolumn{8}{|c|}{ Concentrações em mmol/L } \\
\hline & & & & $\mathrm{Ca}^{2+}$ & $\mathrm{Mg}^{2+}$ & $\mathrm{Na}^{+}$ & $\mathrm{K}^{+}$ & $\mathrm{Fe}^{2+}$ & $\mathrm{Cl}^{-}$ & $\mathrm{SO}_{4}=$ & $\mathrm{HCO}_{3}$ \\
\hline Inicial & 6,0 & 26,8 & 40 & 0,18 & 0,15 & 0,65 & 0,12 & - & 0,91 & 0,009 & 0,35 \\
\hline Final & 7,3 & 39,8 & 904 & 3,22 & 2,45 & 2,48 & 0,41 & 0,02 & 1,77 & 3,91 & 4,12 \\
\hline
\end{tabular}

$\mathrm{O}$ aqüífero $\mathrm{Exu}$, que recebe recarga pluvial no topo da chapada, é um aqüífero livre, i.e., é um sistema aberto em contato com o gás carbônico do solo, com pressão parcial superior que na atmosférica, que induz a dissolução de dióxido de carbono na água, participando na formação de carbonatos (Eqs. 1-4). Devido à litologia da formação, composta de minerais pouco solúveis e com grande resistência ao intemperismo, a água percolada por este solo possui baixa condutividade elétrica (<40 $\mu$ S/cm) (SANTIAGO et al., 1997).

$A$ água do aqüífero Exu possui uma feição cloretada sódica (Figura 2, amostra d'água inicial), embora pela mineralogia e condição de aqüífero livre fosse esperada feição bicarbonatada mista. Esta feição cloretada sódica pode ser explicada através da dissolução de aerossóis marinhos, trazidos por correntes atmosféricas, que entram no aqüífero através da recarga com baixas mas significativas concentrações de cloro e sódio, haja vista a baixa mineralização da água.

A água proveniente do sistema aqüífero superior entra em contato com os três membros da Formação Santana, o que permite 0 desenvolvimento de vários processos hidroquímicos. No membro Romualdo, a dissolução de calcita $\left(\mathrm{CaCO}_{3}\right)$ e de dolomita $\left(\mathrm{CaMg}\left(\mathrm{CO}_{3}\right)_{2}\right)$ (Eqs. 5 e 6) contribui com íons $\mathrm{Ca}^{2+}, \mathrm{Mg}^{2+}$ e $\mathrm{HCO}_{3}{ }^{-}$ mudando a composição química da água de cloretada sódica (porém com baixas concentrações de sais) para bicarbonatada cálcica magnesiana. Esta água apresenta um estágio intermediário não amostrado.

Figura 2 - Estão representadas neste diagrama as amostras d'água inicial (1) e final (2), utilizadas na inversão hidroquímica.

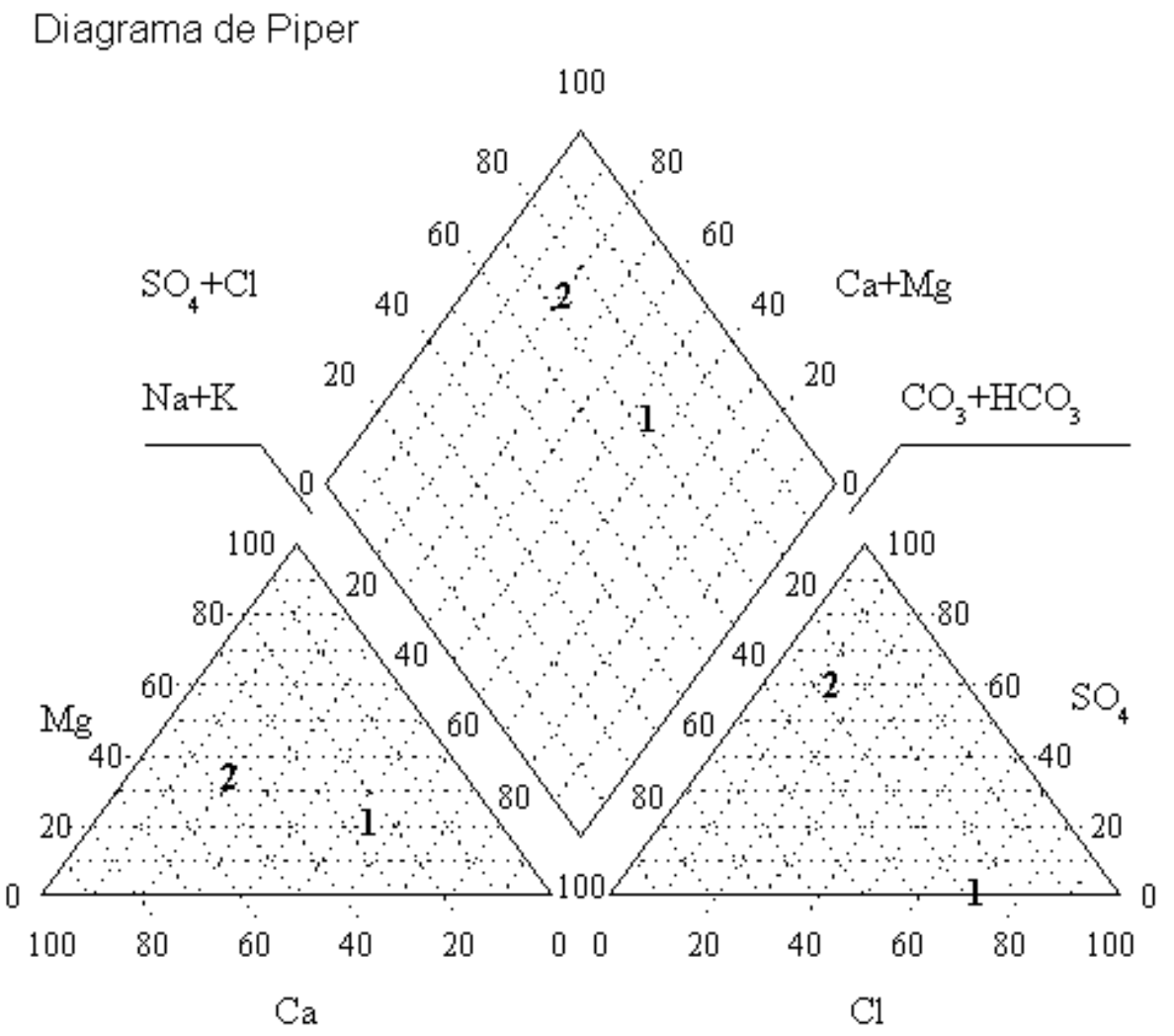


Depois, no Membro Ipubi ocorre dissolução incongruente de gipsita (Eq. 7), porque a água que chega com feição bicarbonatada cálcica magnesiana apresenta alta concentração de cálcio, um elemento comum também à gipsita. À medida, portanto, que a gipsita se dissolve, liberando íons cálcio e sulfato para a solução, haverá conseqüente deposição de calcita $\left(\mathrm{CaCO}_{3}\right)$, retirando íons carbonato da solução e diminuído seu pH (Eqs. 5-7). Este processo torna a água subterrânea sulfatada cálcica magnesiana.

Finalmente, depois de deixar a formação Santana, a água, com altas concentrações de cátions, fluirá pelo aqüífero Rio da Batateira. Devido à presença de argilas neste aqüífero, esperase a ocorrência de processos de troca iônica entre os cátions $\mathrm{Ca}^{2+}, \mathrm{Mg}^{2+}$ e $\mathrm{Na}^{+}$(Eqs. 1618), assim como precipitação de argilas (Eqs. 14 e 15).

A amostra d'água final possui uma concentração de cloretos maior que a da amostra inicial, de maneira que é necessária a adição de uma fase ao modelo que contenha este elemento. Em virtude, entretanto, da ausência deste mineral na mineralogia descrita na atual bibliografia das formações geológicas, postulou-se sua existência na forma de depósitos de halita ( $\mathrm{NaCl})$, formados incipientemente junto com os depósitos evaporíticos do membro Ipubi da formação Santana. Como este mineral é muito solúvel, mesmo a existência de uma pequena quantidade é suficiente para explicar sua adição à solução, conforme mostra a.Tabela 1.

A presença de matéria orgânica no aqüífero proporcionará a atividade biológica de microorganismos que a utilizarão no sentido de obter energia e substâncias necessárias às suas subsistências. Depois que todo o oxigênio dissolvido na água subterrânea tiver sido consumido nos processos bioquímicos de manutenção da vida, outros elementos utilizados como agentes oxidantes tomarão seu lugar, oxidando o carbono existente na matéria orgânica atingindo patamares de potencial eletrônico (pe $=-\log _{10}\left(\left\{e^{-}\right\}\right)$cada vez menores, i.e., ambientes cada vez mais redutores. Este processo leva à redução do íon ferro (Fe(III+) para $\mathrm{Fe}(\mathrm{II}+))(\mathrm{Eq} .10)$ e do enxofre da forma de sulfatos $(\mathrm{S}(\mathrm{VI}+))$ para a forma de sulfetos (S(II-)) (Eq. 11).
$\mathrm{Na}$ inversão hidrogeoquímica, a goethita (Eq. 9) foi utilizada como mineral de ferro por ser o mineral deste elemento que melhor se adapta às condições litológicas da Bacia Sedimentar do Araripe, onde os aqüíferos são constituídos principalmente de arenitos, siltitos e arenitos argilosos pouco consolidados, derivados de formações geológicas que sofreram pouco metamorfismo. O processo bioquímico ocorrerá com a oxidação da matéria orgânica (Eq. 10) através da ação dos microorganismos, induzindo a entrada íons $\mathrm{Fe}(\mathrm{II})$ na solução.

Através destes processos de oxiredução produzidos pelas atividades anaeróbicas de subsistência de microorganismos, dióxido de carbono é adicionado à solução, de acordo com as Eqs. 2-4 e 8, aumentando a concentração total de carbonatos. Deste modo, a existência destes processos no aqüífero poderá modificar sensivelmente a feição da água subterrânea, dependendo da quantidade de material orgânico disponível in sito e da concentração dos agentes oxidantes, assim como do tempo de contato da água com este material. A contribuição relativa destes processos de oxiredução é avaliada através de simulação numérica dos processos químicos termodinâmicos que ocorrem na solução, de modo a poder quantificar os processos que levam a água de seu estágio inicial a ter as características físico-químicas da amostra final (Tabela 1, Figura 2 e Figura 3), ao fim deste processo de evolução hidrogeoquímica.

Foi assumido um potencial eletrônico igual a zero para a amostra de água final, compatível com a alta concentração de ferro (DREVER, 1997) em solução (1,06 mg/L). A presença de sulfetos e $\mathrm{Fe}(\mathrm{II})$ em solução indica a formação de pirita $\left(\mathrm{FeS}_{2}\right)$ que é um mineral praticamente insolúvel e, portanto, tende a precipitar após sua formação, retirando enxofre e ferro da solução.

A formação de pirita em potencial redox ligeiramente maior que aquele para a formação de sulfetos é uma clara indicação de que este mineral será formado tão logo existam sulfetos disponíveis em solução, como indica o diagrama $\mathrm{pH} \times \mathrm{pE}$ (Figura 3), que mostra a distribuição das principais espécies químicas de ferro e enxofre para a amostra d'água final. 
Figura 3 - Este diagrama mostra as diversos campos de estabilidade onde existem os íons ou complexos de ferro e enxofre, para a amostra d'água final. O asterisco indica a posição da amostra d'água final. As linhas contínuas referem-se aos compostos de ferro e as tracejadas aqueles de enxofre.

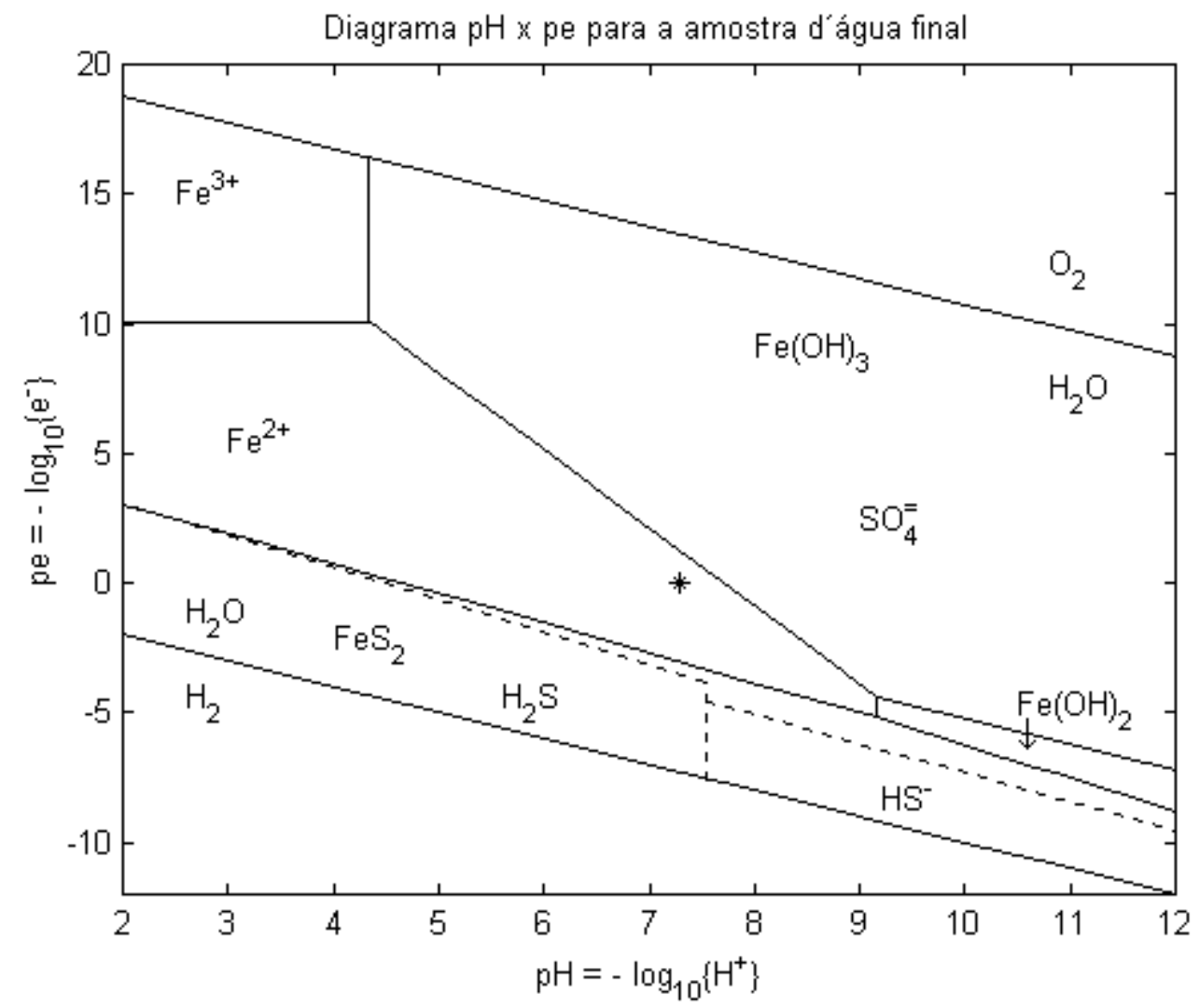

Devido às condições particulares existentes neste sistema aqüífero, na simulação foi assumido que os processos envolvendo a dissolução de gipsita e a precipitação de calcita, assim como a troca iônica de $\mathrm{Ca}^{2+}$ por $\mathrm{Na}^{+}$através do substrado formado pelas argilas, devem necessariamente existir. Por outro lado, admitiu-se poder ocorrer processos de dissolução de dolomita, feldspatos e goethita, reações de oxiredução com a utilização da matéria orgânica; precipitação de pirita e das argilas, além do que se permitiu troca iônica do íon $\mathrm{Mg}^{2+-}$.

Com estas condições restritivas, com os dados das amostras d'água (Tabela 1) e as fases referentes aos processos geoquímicos descritos na seção 3,0 PHREEQC (PARKHURST e APPELO, 1999) fornece dois resultados, ambos plausíveis, expostos na Tabela 2, onde os valores de concentrações positivos representam adição da fase à solução, i.e., dissolução e os negativos, subtração da solução, i.e., precipitação do mineral. 
Tabela 2 - Transferência molar das fases em mmol/L

\begin{tabular}{l|l|c|c}
\hline \multirow{2}{*}{ Fase } & \multicolumn{2}{|c}{ Fórmula química } & \multicolumn{2}{c}{ Simulação } \\
\cline { 3 - 4 } & & 1 & 2 \\
\hline Gipsita & $\mathrm{CaSO}_{4} \cdot 2 \mathrm{H}_{2} \mathrm{O}$ & 6,03 & 6,54 \\
\hline Calcita & $\mathrm{CaCO}_{3}$ & $-4,88$ & $-5,59$ \\
\hline Dolomita & $\mathrm{CaMg}\left(\mathrm{CO}_{3}\right)_{2}$ & 2,36 & 2,24 \\
\hline Halita & $\mathrm{NaCl}$ & 0,82 & 0,82 \\
\hline CH2O & $\mathrm{CH}_{2} \mathrm{O}$ & 3,78 & 4,73 \\
\hline Goethita & $\mathrm{FeOOH}$ & 1,02 & 1,28 \\
\hline Pirita & $\mathrm{FeS}_{2}$ & $-1,01$ & $-1,26$ \\
\hline Anorthita & $\mathrm{CaAl}_{2} \mathrm{Si}_{2} \mathrm{O}_{8}$ & 0,030 & 0,37 \\
\hline Albita & $\mathrm{NaAlSi}_{3} \mathrm{O}_{8}$ & 0,00 & 0,00 \\
\hline K-feldspato & $\mathrm{KaISi}_{3} \mathrm{O}_{8}$ & 0,30 & 0,30 \\
\hline Ca-Montmorilonita & $\mathrm{Ca}_{0,165} \mathrm{Al}_{2,33} \mathrm{Si}_{3,67} \mathrm{O}_{10}(\mathrm{OH})_{2}$ & 0,00 & $-0,45$ \\
\hline Na-Montmorilonita & $\mathrm{Na}_{0,5} \mathrm{Al}_{1,5} \mathrm{Mg}_{0,5} \mathrm{Si}_{4} \mathrm{O}_{10}(\mathrm{OH})_{2}$ & $-0,24$ & 0,00 \\
\hline CaX2 & $\mathrm{CaX}_{2}$ & $-0,59$ & $-0,53$ \\
\hline NaX & $\mathrm{NaX}$ & 1,17 & 1,05 \\
\hline
\end{tabular}

Ambos os modelos não apresentam diferença em relação à dissolução de Halita e de feldspato potássico (K-feldspato), porque estes minerais são as únicas fontes de cloretos, o primeiro, e de potássio, o segundo. Por outro lado, nenhum dos dois apresentou dissolução de Albita, indicando a inexistência de quantidades importantes deste mineral nas rochas que compõem as formações geológicas por onde passa a água subterrânea.

A maior diferença entre estes dois resultados encontra-se na precipitação das argilas. O primeiro resultado apresenta precipitação de montmorilonita sódica acompanhado de uma relativamente pequena dissolução de Anorthita (feldspato cálcico), enquanto que o segundo, ao contrário, apresenta precipitação de montmorilonita cálcica com dissolução de uma quantidade quase dez vezes maior de Anorthita, comparado com 0 primeiro resultado. Na ausência de um mapeamento mais detalhado da mineralogia das formações geológicas não é possível eleger, dentre estes dois resultados, o que melhor representa o que acontece neste caminho de fluxo regional. Possivelmente, uma combinação de ambos os resultados pode ser o que realmente acontece na evolução química da água.

\section{Conclusão}

Para que a água armazenada no aqüífero Rio da Batateira na zona confinada localizada na Chapada do Araripe adquira a composição química determinada experimentalmente, é necessário que ela tenha entrado em contato com minerais como gipsita, calcita e dolomita. A presença destes minerais apenas no aquiclude Santana leva a concluir a existência de fluxo através desta formação, corroborando com o modelo fenomenológico apresentado por SANTIAGO et al. (1997), que propôs um caminho de fluxo através de falhas e fraturas existentes nas rochas desta formação.

\section{Agradecimentos}

Ao apoio logístico dado pela COGERH (Companhia de Gestão de Recursos Hídricos do Estado do Ceará) na pessoa do Dr. Valber Cordeiro.

\section{Bibliografia}

ASSINE, M. L., Análise Estratigráfica da Bacia do Araripe, Nordeste do Brasil, Revista Brasileira de Geociências, v. 22, n. 3, p. 289-300, 1992.

BEURLEN, K., As Condições Ecológicas e Faciológicas da Formação Santana, na Chapada do Araripe (Nordeste do Brasil).

Anais da Academia Brasileira de Ciências, Rio de Janeiro, v. 43, p. 411415, 1971. 
DNPM, Projeto Avaliação Hidrogeológica da Bacia Sedimentar do Araripe. Recife: 1996.

DNPM, Programa Nacional de Estudos dos Distritos Mineiros - Projeto Gipsita. Recife: 1995.

DREVER, J. I. The Geochemistry of Natural Waters, 3 ed. Upper Saddle River, NJ: Prentice-Hall, 1997.

JACOMINE, P. K., ALMEIDA, J. C., MEDEIROS, L. A. R. Boletim Técnico 28, convênio MA/DNPEA SUDENE/DRN. Levantamento exploratório - reconhecimento de solos do Estado do Ceará. Recife: 1973.

MENDONÇA, L. A. R. Recursos Hídricos da Chapada do Araripe. Ceará, 2001. Tese (Doutorado em Recursos Hídricos). Centro de Tecnologia - Universidade Federal do Ceará.

OLIVEIRA, A. A. Calcáreos Laminados do Cariri, Ceará, 1988. Dissertação (Mestrado em Geologia). Centro de Ciências - Universidade Federal do Ceará.

PARKHURST, D. L., APPELO, C. A. J. User's guide to PHREEQC - a computer program for speciation, batch-reaction, one-dimensional transport, and inverse geochemical calculations. Colorado: 1999. U. S.
Geological Survey, Water-Resources Investigations Report 99-4259 .

PONTE, F. C., APPI, C. J. Proposta de revisão da Coluna Estratigráfica da Bacia do Araripe. XXXVI CONGRESSO BRASILEIRO DE GEOLOGIA, (1990, Natal), v. 1, p. 211-226, 1990.

SANTIAGO, M. M. F., SILVA, C. M. S. V., MENDES FILHO, J. AND FRISCHKORN, $\mathrm{H}$., Characterization of Groundwater in the Cariri (Ceará, Brazil) by Environmental Isotopes and Electric Conductivity, Radiocarbon, v. 39, n. 1, pp 49-59, 1997.

SILVA, C. M. S. V. Modelo fenomenológico para a circulação de água na bacia sedimentar do Cariri com base em isótopos e hidroquímica. 1996. 162 f. Tese (Doutorado em Física) - Centro de Ciências, Universidade Federal do Ceará, Fortaleza.

SILVA, M. A. M., 1983, The Araripe Basin, Northeastern Brazil: Regional Geology and Fácies Analysis of a Lower Cretaceous Evaporitic Depositional Complex, EUA, 290p, (Tese de Doutoramento, Columbia University).

SILVA, M. A. M., 1988, Evaporitos do Cretáceo da Bacia do Araripe: ambientes de deposição e história diagenética. Bol. Geoc. PETROBRÁS, 2(1):53-63 